\title{
Los acuerdos prematrimoniales en derecho internacional privado español
}

\author{
Prenuptial Agreements in Spanish Private International Law \\ Os acordos pré-nupciais no direito internacional privado espanhol
}

\author{
ISABEL ANTÓN JUÁREZ*
}

FeCha de ReCepción: 17 de Julio de 2018. Fecha de AProbación: 19 de SePtiembre de 2018

DoI: http://dx.doi.org/10.12804/revistas.urosario.edu.co/sociojuridicos/a.7256

Para citar este artículo: Antón Juárez, I. (2019). Los acuerdos prematrimoniales en derecho internacional privado español. Estudios Socio-Jurídicos, 21(1), 61-90. Doi: http://dx.doi.org/10.12804/revistas.urosario.edu.co/sociojuridicos/a.7256

\section{RESUMEN}

Los acuerdos prematrimoniales son una figura cada vez más frecuente en el tráfico jurídico internacional. Atrás quedó la concepción de que se trata de un negocio jurídico relegado a ricos y a estrellas del cine. En la actualidad, debido a la movilidad de las personas, los matrimonios en los que los cónyuges no comparten nacionalidad son bastantes frecuentes. Sin embargo, igual que la frecuencia en su celebración es habitual también que acaben en divorcio. Por este motivo, muchos de ellos deciden regular, mediante un acuerdo prematrimonial, los efectos de una posible ruptura. El objeto de nuestro estudio es el análisis de estos pactos desde un punto de vista internacional privatista. Como consecuencia de los diferentes elementos extranjeros que pueden presentar estos pactos, resulta necesario determinar qué derecho resulta de aplicación para saber si son válidos. Para llegar a tal derecho es necesario tener en cuenta las normas de derecho internacional privado. En particular, centraremos el estudio en el Artículo 9.3 del Código Civil español.

Palabras clave: acuerdo prematrimonial, ley aplicable, cónyuge, derecho internacional privado.

* Doctora en Derecho por la Universidad Carlos III de Madrid. Profesora ayudante doctor de Derecho Internacional Privado en la Universidad Carlos III de Madrid. Secretaria de redacción de la revista jurídica Cuadernos de Derecho Transnacional. Sus líneas de investigación se centran en el derecho europeo de la competencia y la distribución comercial, el derecho procesal civil internacional y el derecho de familia internacional. Correo electrónico: isabel.anton@uc3m.es ORCID: https://orcid.org/0000-0002-5369-2301. 


\section{ABSTRACT}

Prenuptial agreements are common nowadays in an international context. The idea that it is a legal business relegated to rich people and movie stars has been ruled out. Currently, due to the mobility of people, marriages in which the spouses do not share nationality are quite frequent. However, just as the frequency in their celebration is also usual to end in divorce. With this motive, many of them decide to regulate through a prenuptial agreement the effects of a possible rupture. The object of our paper is the analysis of these pacts from an international privatist point of view. As a result of the different foreign elements that can present these pacts, it is necessary to determine which law is applicable to know if they are valid. To reach such a law, it is necessary to take into account the rules of private international law. In particular, we will focus the study on article 9.3 of the Spanish Civil Code.

Keywords: Prenuptial agreement, applicable law, spouse, private international law.

\section{RESUMO}

Os acordos pré-nupciais são uma figura cada vez mais frequente no tráfico jurídico internacional. Para atrás ficou a conceção de que se trata de um negócio jurídico relegado a ricos e estrelas do cinema. Na atualidade, devido à mobilidade das pessoas, os casamentos nos que os cônjuges não partilham nacionalidade são bastante frequentes. No entanto, igual que a frequência em sua celebração, é habitual também que acabem em divórcio. Com este motivo, muitos deles decidem regular mediante um acordo pré-nupcial os efeitos de uma possível rutura. O objeto de nosso estudo é a análise destes pactos desde um ponto de vista internacional privatista. Como consequência dos diferentes elementos estrangeiros que podem apresentar estes pactos, resulta necessário determinar que direito resulta de aplicação para saber se são válidos. Para chegar a tal direito é necessário ter em conta as normas de Direito Internacional Privado. Em particular, centraremos o estudo no Art. 9.3 do código civil espanhol.

Palavras-chave: acordo pré-nupcial, lei aplicável, cônjuge, direito internacional privado. 


\section{Introducción}

El objeto del presente es el estudio de la figura de los acuerdos prematrimoniales desde una disciplina concreta: el derecho internacional privado español. El próximo 29 de enero de 2019 comenzará a ser de aplicación el Reglamento (UE) 2016/1103 del Consejo, de 24 de junio de 2016, por el que se establece una cooperación reforzada en el ámbito de la competencia, la ley aplicable, el reconocimiento y la ejecución de resoluciones en materia de regímenes económicos matrimoniales ${ }^{1}$. El objeto de nuestro estudio no será este reglamento, sino el análisis del estado de la cuestión con anterioridad a la aplicación de esta norma. Esto es así porque las normas de derecho internacional privado españolas, en materia de efectos del matrimonio (artículos 9.2 y 9.3 Código Civil), se van a seguir aplicando por los jueces españoles en el caso de los acuerdos prematrimoniales para todos aquellos pactos celebrados antes del 29 de enero de 2019. Por ese motivo, consideramos que todavía es necesario y relevante un estudio de las normas de derecho internacional privado españolas sobre la cuestión.

\section{Concepto y objetivo de los acuerdos prematrimoniales}

Los acuerdos entre futuros cónyuges, antes de contraer matrimonio, son habitualmente conocidos como acuerdos prematrimoniales, prenupcial agreements o prenups. Las partes que celebran estos acuerdos buscan, ante todo, que los efectos económicos que va a producir su matrimonio queden regulados de acuerdo a los criterios que ellos mismos consideran oportunos. Esta regulación que las partes pueden llevar a cabo se va a ocupar, principalmente, de fijar el régimen económico matrimonial por el que van a regir los cónyuges y establecer una posible liquidación en caso de divorcio - reparto de bienes, uso de los mismos, renuncia de derecho-. En definitiva, un acuerdo prematrimonial pretende dejar al margen a las autoridades judiciales en el reparto del patrimonio de los cónyuges una vez se ha producido la ruptura. Sin embargo, este tipo de

1 DOUE L 183/1, de 8 de julio de 2016. 
pactos puede ir más allá y no solo regular las cuestiones económicas que afectan a los cónyuges. Las partes ponen los límites. Así, los futuros cónyuges pueden, en un prenupcial agreement, regular cuestiones personales de su convivencia o incluso relativas a hijos que todavía no han nacido.

Los famosos estadounidenses saben bien qué incluir en un prenup, así, por ejemplo, en el acuerdo prematrimonial de Mark Zuckerberg y Priscilla Chang se incluyó la obligación de verse en persona al menos una vez por semana y que dicho encuentro no podría tener una duración inferior a una hora y cuarenta minutos. Tras varios fracasos anteriores, Nicole Kidman lo tenía claro: si su futuro marido, el cantante Keith Urban, recaía en las drogas, no recibiría nada de su patrimonio; sin embargo, si se portaba bien, su recompensa sería 640000 dólares por año de convivencia.

Aunque es cierto que esta figura contractual de tradición anglosajona no ha sido demasiado habitual en países como España, cada vez su presencia es más notoria en los ordenamientos europeos. Algunas de las razones que explican su auge son (Antón, 2015; Rodríguez Guitán, 2018): 1) matrimonios mixtos. Los matrimonios donde los cónyuges no comparten la nacionalidad son muy frecuentes. Para estos, el acuerdo prematrimonial es una vía excelente para fijar la ley que va a regir los efectos del matrimonio, fijar el régimen económico matrimonial y así restar inseguridad a un posible divorcio internacional; 2) alto índice de divorcios. España es un ejemplo de país donde existe un alto índice de divorcios $^{2}$. Las parejas son cada vez más conscientes de que un prenup es una vía para mitigar los efectos de una ruptura. La previsión de sus efectos económicos de antemano puede ser una gran ventaja; 3) segundas $y$ sucesivas nupcias. La necesidad de un prenup, tras un fracaso amoroso anterior, puede ser imperiosa. Hijos de anteriores relaciones, ser socio de la empresa familiar, bienes que ha costado mucho esfuerzo conseguir, entre otros, son motivos que animan a futuros contrayentes a pensar en un acuerdo prematrimonial. 


\section{Las posibilidades de los prenups en el derecho internacional privado español}

\section{Aproximación inicial}

Los acuerdos prematrimoniales no son pactos fáciles desde una perspectiva jurídica. En primer lugar, una de las incertidumbres que se plantean es acerca de su naturaleza: ¿es un mero contrato civil o tiene naturaleza especial? A esto se le une que, salvo en determinados ordenamientos forales, como el catalán, no está expresamente regulado en el ordenamiento jurídico español ${ }^{3}$. Pero, quizás, estas cuestiones enunciadas no son tan problemáticas como hasta dónde podría llegar la autonomía de la voluntad de las partes. Es decir, el pacto sobre el reparto de bienes, la renuncia a la pensión compensatoria o incluso a la pensión de alimentos por uno de los cónyuges son cuestiones que han sido estudiadas por la doctrina y también por la jurisprudencia, para llegar a la conclusión de que los cónyuges tienen reconocida una amplia autonomía de la voluntad para pactar lo que consideren oportuno.

Dicha autonomía encuentra como límite, en el ordenamiento español, el Artículo 1255 del Código Civil (en adelante, CC). Este precepto señala lo siguiente: "Los contratantes pueden establecer los pactos, cláusulas y condiciones que tengan por conveniente, siempre que no sean contrarios a las leyes, la moral, ni al orden público". Así, cabría preguntarse, al tenor de la amplia interpretación que puede tener dicho Artículo 1255 CC, si se puede pactar en un prenup la custodia de los hijos o su régimen de visitas, incluso cuando estos ni si quiera han nacido, si es posible crear una sociedad mercantil entre los cónyuges en el mismo acuerdo o hacer donaciones.

Además, otro hándicap que presentan los acuerdos prematrimoniales es que se firman antes de la celebración del matrimonio. Esta cuestión tiene su importancia cuando el acuerdo se hace valer ante un juez mucho tiempo después de su firma y bajo circunstancias que no se parecen en absoluto al momento en el que se concluyó. Pero el análisis sobre

3 Ley 25/2010, de 29 de julio, del Libro Segundo del Código Civil de Cataluña, relativo a la persona y la familia (BOE núm. 203, de 21 de agosto de 2010). 
la validez del prenupcial agreement puede complicarse aún más cuando existen elementos extranjeros en la relación. Ad ex., los futuros cónyuges no comparten nacionalidad, residen en diferentes Estados o tienen bienes en más de un país. En estos casos donde hay conexión con más de un ordenamiento, las partes firmantes de un prenup puede que no solo hayan hecho uso de la autonomía de la voluntad material -detallar el contenido del pacto- sino también de su autonomía de la voluntad conflictual -elegir la ley aplicable a dicho pacto entre las posibles que podrían resultar de aplicación-.

De este modo, son muchos y muy variados los entresijos legales que plantean los acuerdos prematrimoniales para todo aquel que, por una razón u otra, deba analizar su validez y su peso ad ex. en un divorcio internacional o en una liquidación del régimen económico matrimonial. Así, un juez español al que se le plantee la validez de un prenup celebrado en Inglaterra entre inglesa y español que residen habitualmente en España y que desean divorciarse tras quince años de matrimonio, antes que ninguna otra cuestión deberá determinar la ley aplicable a dicho pacto. A esta ley se llegará al aplicar el sistema de derecho internacional privado español y será la que responda a cuestiones como si el pacto es válido, cómo debe interpretarse y su peso en el caso concreto.

\section{La calificación del acuerdo prematrimonial conforme el derecho internacional privado español}

Para determinar la ley aplicable a un acuerdo prematrimonial, es necesario precisar la norma de conflicto aplicable. En derecho internacional privado español no existe una norma de conflicto específica para el prenup. Al tratarse de una figura semidesconocida para el ordenamiento jurídico español, es necesario calificar (Calvo \& Carrascosa González, 2017, pp. 260-261). La determinación de la norma de conflicto aplicable a los acuerdos prematrimoniales en derecho internacional privado español podría llevarse a cabo por dos vías:

1) Tesis de la calificación por la función. El objeto de esta tesis consiste en analizar la función de la institución jurídica extranjera conforme al ordenamiento extranjero al que pertenece para poder encontrar en 
el ordenamiento del foro otra figura conocida que desempeñe una función similar (Calvo \& Carrascosa González, 2017, p. 484). El estudio del derecho inglés y del derecho estadounidense, como ordenamientos donde los acuerdos prematrimoniales tienen tradición jurídica, permite delimitar, perfectamente, la función que desempeñan los prenups en el tráfico jurídico. Dicha función es muy parecida a la que realizan las capitulaciones matrimoniales en nuestro ordenamiento jurídico ${ }^{4}$, figura jurídica que sí está regulada de forma expresa en nuestro ordenamiento interno. Las capitulaciones matrimoniales sí disponen de una norma de conflicto que permite determinar la ley aplicable. Se trata del Artículo 9.3 CC.

2) Tesis de los conceptos amplios positivos. El supuesto de hecho de determinadas normas de conflicto se amplía por el legislador de forma deliberada con el fin de que tengan cabida figuras no conocidas por el derecho español. Esto da lugar a que el concepto que se utiliza como supuesto de hecho sea amplio. Esto sucede en el Artículo 9.3 CC. Así, es posible incluir dentro del supuesto de hecho del Artículo 9.3 CC, no solo los acuerdos prematrimoniales sino también cualquier otro pacto entre los cónyuges dirigido a regular los efectos económicos del matrimonio. La denominación del pacto en el derecho extranjero o la denominación que le hayan atribuido las partes es totalmente indiferente para la aplicación del Artículo 9.3 CC al mismo (Calvo Caravaca \& Carrascosa, 2017).

Así, podemos decir que para incluir un negocio que celebren los cónyuges o futuros cónyuges dentro del supuesto del hecho del Artículo 9.3 CC se deben cumplir dos requisitos: 1) ser un pacto dirigido a regular los efectos del matrimonio; 2) se trate de un supuesto internacional.

4 En este sentido lo ha considerado también el Tribunal Supremo en su Sentencia de 24 de junio de 2015, No.. 392/2015, sala de lo Civil, Secc. 1ª, Recurso de Casación 2393/2013, ponente Excmo Sr. Francisco Javier Arroyos Fiestas, FJ $5^{\circ}$. 


\section{La ley aplicable al acuerdo prematrimonial}

Unidad de ley para el análisis de la validez del fondo del prenup

Como ya se ha puesto de manifiesto, los acuerdos prematrimoniales son pactos que pueden contener disposiciones de muy diversa naturaleza: se puede pactar todo lo que los futuros cónyuges consideren oportuno. De este modo, debido a que el prenup carece de norma de conflicto específica y a que en los mismos se pueden incluir aspectos económicos y también personales, surgen dudas en cuanto a la ley aplicable a estos pactos. En un apartado previo se llegó a la conclusión de que, debido a que la función del prenup es prácticamente la misma que la de las capitulaciones matrimoniales, es posible aplicar la norma de conflicto que existe en nuestro ordenamiento para este tipo de pactos. Por lo tanto, el Artículo 9.3 CC podía aplicarse también a un acuerdo prematrimonial para especificar qué ley determina su validez. Sin embargo, apuntando de nuevo a ese clausulado tan variado que podría recoger un prenup surge desde una visión internacional privatista una cuestión, y es si sería posible aplicar al acuerdo prematrimonial, para determinar su validez, una única norma de conflicto y que así sea posible aplicar al prenup una única ley para determinar su validez o si se debe fraccionar el prenup en atención a su contenido y, por tanto, aplicar tantas normas de conflicto como diferentes contenidos existan.

En relación a la segunda opción planteada, el prenup debería "desmembrarse", fracturarse, en definitiva, dividirse en función de las materias que incorpora (Calvo \& Carrascosa, 2017, p. 261). Así, se deberían aplicar tantas normas de conflicto como cláusulas sobre diferentes materias existan. De este modo, debería tenerse en cuenta no solo el Artículo 9.3 CC sino también otras normas de conflicto, como el Artículo 9.4 CC (relativo a las cuestiones de filiación y también a otros aspectos paternofiliales como pueden ser las líneas a seguir en la educación de los hijos), el Protocolo de la Haya de 23 de noviembre de 2007 (para lo referente a alimentos, bien entre los futuros cónyuges o entre estos y sus posibles hijos) o el Convenio de la Haya de 19 de octubre de 1996 (aplicable a las medidas de protección de los menores como la custodia o el régimen de visitas). De este modo, según esta visión para determinar la ley aplicable 
al acuerdo, es necesario estudiar su contenido. Este análisis permitirá saber las materias de las que se ocupa el prenup y si es necesario aplicar más de una norma de conflicto a un único acuerdo.

Así, ad ex., el prenup de una pareja que reside en Madrid -él alemán, ella inglesa- donde acuerda su régimen económico matrimonial (el régimen de participación en ganancias alemán), fijan la pensión de alimentos para los futuros hijos y el régimen de visitas que en caso de divorcio podría existir sobre aquellos, es posible que quede regulado del siguiente modo si un juez español tuviera que analizarlo siguiendo esta tesis. Dicho operador jurídico debería tener en cuenta tres normas de conflicto -la norma de conflicto aplicable para el régimen económico matrimonial pactado (Artículo 9.3 CC), la norma de conflicto aplicable a los alimentos (Protocolo de la Haya de 23 de noviembre de 2007) y la norma de conflicto aplicable a la protección de menores (Convenio de la Haya de 19 de octubre de 1996) - para saber si dichas cláusulas son o no válidas. Dichas normas de conflicto determinarán la aplicación de unas determinadas leyes a cada cuestión, que pueden o no coincidir, y son las que van a establecer si las partes han hecho un ejercicio correcto de su autonomía de la voluntad y, por tanto, si la cláusula incorporada en el acuerdo es válida.

Es más, hay autores que consideran que la posibilidad de incorporar un contenido diferente al estrictamente patrimonial implica que la validez de dichas cláusulas deba superar un doble análisis. A esas cláusulas se les debe aplicar la ley establecida por la norma de conflicto específica a la materia (lex causae) y también la ley que rige el pacto capitular. Es decir, si en un prenup se estableciera una pensión de alimentos a favor de los hijos, se debería acudir a la norma de conflicto existente sobre esa materia en el ordenamiento que comprueba la validez del pacto (Protocolo de la Haya de 23 de noviembre de 2007, en el caso español), y sería la ley a las que nos lleve dicha norma (lex causae) la que determine si es posible la inclusión de ese tipo de estipulación en un pacto entre futuros cónyuges (Rodríguez Pineau, 2002). Pero no acaba ahí, también sería necesario comprobar si conforme a la ley que rige el pacto matrimonial, la inclusión de ese tipo de cláusulas es válido en ese tipo de acuerdos. De acuerdo a la óptica del derecho español, no habría problema debido a que en un contrato capitular se pueden incluir cuestiones estrictamente referidas al 
régimen económico matrimonial, pero también otras que nada tengan que ver. Sin duda, la tarea para el juez es ingente y difícil, sobre todo por el hándicap que tenemos en España de que, bien por falta de medios, formación o interés se huya de la aplicación del derecho extranjero a toda costa. También esta visión presenta problemas para las partes. Estas deberían tener que probar más de un derecho extranjero en un proceso. Si probar un derecho extranjero resulta complicado, probar, en un mismo procedimiento, varias leyes extranjeras complica todo aún más. Además, esta posición aumentaría el coste económico para las partes y es un esfuerzo extra que les puede desincentivar a hacer valer su pacto. El resultado podría ser que se quedara el pacto en papel mojado por el miedo al litigio.

Con base en lo anterior, en un prenup que incluya cuestiones muy diferentes entre sí puede darse la situación de que sea válido solo en parte; imaginemos que las cuestiones que afectan al régimen económico matrimonial se rigen por la ley X. Sin embargo, las cuestiones que afectan a los alimentos de los cónyuges se rigen por la ley Z. Si la citada ley X no permite el pacto sobre la pensión alimenticia, lo estipulado por las partes no será válido. Esta situación, que las partes se encuentren con que su pacto solo es válido en partes, no ayuda a la seguridad jurídica del tráfico internacional. Además, otro problema es la falta de previsibilidad que puede ocasionar la fragmentación del prenup por materias. Las partes, salvo que conozcan el derecho internacional privado o se encuentren muy bien asesoradas, no van a esperar que la ley aplicable a su pacto puedan ser varias leyes que podrán, o no, dar validez a la parte del pacto para la que se aplique.

Así, entendemos que el Artículo 9.3 CC, por tratarse de la norma de conflicto aplicable a los pactos entre cónyuges, se podría ocupar de determinar si el acuerdo es válido en su conjunto. Es decir, con independencia de su contenido, se aplicaría una única norma de conflicto: el Artículo 9.3 CC. La ley a la que remitiera dicha norma de conflicto regularía tanto las cuestiones económicas que tuvieran relación con el régimen económico matrimonial como otras de diferente naturaleza que pudieran existir. Esta opción podría llevar a que solo una ley se aplicara a todo el acuerdo para determinar su validez. Ad ex., en un acuerdo prematrimonial entre española y francés, ambos pactan que la ley aplicable 
a su pacto sea el derecho francés, que el régimen económico matrimonial elegido es el de separación de bienes, que el esposo tendría derecho a una renta vitalicia de 1000 euros y que la vivienda familiar pasaría a titularidad de la esposa en caso de divorcio; además, establecen que, en caso de tener hijos, la educación debe basarse en la fe católica. De acuerdo con esta tesis, al tratarse de un pacto entre futuros cónyuges, asimilable a las capitulaciones matrimoniales, la norma de conflicto aplicable debería ser el Artículo 9.3 CC con independencia de las materias que recoja el acuerdo. Así, la ley a la que nos lleve el Artículo 9.3 CC será la que determine la validez del pacto.

La base jurídica que sustenta esta tesis podría descansar en los siguientes argumentos:

a) Concepto actual amplio de capitulaciones matrimoniales. Un amplio sector doctrinal considera que el objeto de las capitulaciones matrimoniales puede versar no solo sobre aspectos económicos relacionados con el régimen económico matrimonial, sino también sobre otro tipo de aspectos económicos - reparto de bienes, fijación de la cuantía de pensión de alimentos, renuncia a la pensión compensatoria, donación de bienes futuros en caso de muerte-, e incluso aspectos personales -fijación del domicilio, educación de los hijos, etc.- - El hecho de que se incluyan cuestiones diferentes a las relacionadas con la economía de los cónyuges no hace que el acuerdo deje de ser considerado como capitulaciones matrimoniales en el ordenamiento interno (Medina, Heras \& Iglesias, 2014, p. 477). Además, tal como señala el Artículo 1326 CC los capítulos matrimoniales pueden pactarse tanto antes de la celebración del enlace como después. De este modo, los prenups sí podrían encajar dentro de lo que en la actualidad se entiende por capitulaciones matrimoniales. Así, para estos pactos sí hay una norma de conflicto específica: el Artículo 9.3 CC.

b) Función económica predominante del acuerdo prematrimonial. Los acuerdos prematrimoniales, como ya se ha señalado, son de un tipo que puede incluir cualquier tipo de cláusula que los futuros cónyuges consideren oportuna. Sin embargo, hay unas que son más comunes y que, por lo general, mueven a las partes a celebrar este tipo de acuerdos. Estas son las de naturaleza patrimonial o económica. Es decir, las 
estipulaciones que determinan o prevén los efectos patrimoniales del matrimonio. Por tanto, la función del prenup es conocida en nuestro ordenamiento y desarrollada por una figura jurídica conocida como capitulaciones matrimoniales. Así, se podría decir que el contenido que pretende regular las cuestiones patrimoniales de los futuros cónyuges es el contenido principal de la mayoría de los acuerdos prematrimoniales que se celebran. Esto así porque concuerda con el propio ser del acuerdo y que lo diferencia de otro tipo de acuerdos entre cónyuges - los celebrados durante el matrimonio o cuando el matrimonio ya está roto- y es evitar los efectos económicos negativos o imprevistos que podría ocasionar la ruptura matrimonial.

El hecho de que se destaque esta función económica del acuerdo prematrimonial sobre otras que podría cumplir -fijar la custodia de los hijos, su educación, deberes personales, etc.- no le resta libertad a las partes a la hora de negociar. El contenido del acuerdo prematrimonial vendrá marcado por la ley que rija el acuerdo. Ese ordenamiento es el que determinará si los cónyuges pueden pactar o no sobre determinadas materias. Aunque no siempre exista una semejanza total entre el prenup y las capitulaciones, lo importante es que sí haya una equivalencia suficiente entre la figura jurídica desconocida extranjera y la figura jurídica conocida en derecho español. Dicha equivalencia existe, sin duda, entre los acuerdos prematrimoniales y las capitulaciones matrimoniales.

c) No se transgrede el ámbito de aplicación del Artículo 9.3 CC. El Artículo 9.3 CC es la norma de conflicto del sistema de derecho internacional privado español para determinar "la validez" de los pactos o capitulaciones matrimoniales. Es decir, si el acuerdo es válido o no nos lo debe decir la ley a la que lleva el Artículo 9.3 CC. Esa es la ley a la que hemos llegado vía Artículo 9.3 CC, que determina hasta dónde puede llegar la autonomía material de los cónyuges, qué cláusulas son permitidas a la luz de ese ordenamiento. En otras palabras, la validez del pacto, en su conjunto (contenga una cláusula o cien, compartan o no naturaleza entre sí), se determinará conforme al derecho o derechos (no podemos olvidar los puntos de conexión alternativos) a los que nos lleve el Artículo 9.3 CC. Esto permite analizar el pacto bajo una única norma de referencia. Bajo nuestro punto de vista no 
se transgrede el ámbito de aplicación del Artículo 9.3 CC, ya que la observancia de la validez material del pacto está incluida dentro de su ámbito de aplicación. Esto permite que las partes no se vean sorprendidas por la aplicación de diferentes normas de conflictos que llevan a diferentes leyes; en definitiva, se reduce el coste conflictual. Pero hay una cuestión importante: es necesario tener en cuenta que, así sea el Artículo 9.3 CC la norma de conflicto aplicable para determinar la validez del prenup en su conjunto, porque su ámbito de aplicación lo permitiría, no quiere decir que las partes voluntariamente fragmenten el acuerdo y apliquen dos, tres o más leyes porque así lo han decidido. Pero lo han elegido ellas y, es más, como se verá, el Artículo 9.3 CC permite este fraccionamiento legal.

No obstante, que se aplique una única norma de conflicto a todo el pacto para que se analice el acuerdo en su totalidad bajo un ordenamiento no quiere decir que todas las cláusulas del prenup sean válidas. Puede ser que las partes se excedan y haya cláusulas nulas. Aunque, a decir verdad, existe más probabilidad de que, bajo el prisma de la misma ley aplicable, el pacto sea válido en su conjunto. Esto es así porque lo normal es que cuando redactas este tipo de pactos, lo haces teniendo en cuenta un ordenamiento jurídico (aunque no se señale expresamente), sobre todo cuando se ha recibido asesoramiento. El hecho de que la cláusula tenga más posibilidades de ser válida se alinea con el objetivo del Artículo 9.3 CC que, con sus puntos de conexión alternativos, busca la validez de lo estipulado por las partes.

Por lo tanto, consideramos que el hecho de que la validez del pacto se analice bajo una única ley podría ser la solución a seguir por el operador jurídico que tuviera que enfrentarse a la validez de este tipo de pactos. A nuestro modesto entender, esta tesis no está exenta de problemas, pero podría presentar los siguientes aspectos positivos:

1) Fomenta la validez del pacto. La aplicación de una única ley fomenta que el pacto en su totalidad sea válido y, por tanto, que se respete la autonomía de la voluntad de las partes en la regulación de los efectos de su matrimonio. Además, esta posición podría estar más acorde con 
el espíritu del Artículo 9.3 CC que, como se va a estudiar, persigue la validez del acuerdo mediante sus puntos de conexión alternativos.

2) Refuerza la previsibilidad de la ley aplicable. Las partes no se ven sorprendidas por la aplicación de más de una norma de conflicto que puede derivar en más de una ley, aspecto que, en principio, no esperan y que puede implicar un importante coste para los cónyuges.

3) Carácter práctico. La tarea del juez o del operador jurídico que deba enfrentarse al análisis de un prenup se simplifica si la norma de conflicto conforme a la que debe determinar la validez del acuerdo prematrimonial es solo una. También presenta ventajas a la hora de probar el derecho extranjero.

Otros aspectos a controlar para que el prenup sea válido conforme al derecho internacional privado español

Junto con la validez de fondo, es necesario también el análisis de otros aspectos para determinar la validez del pacto prenupcial. Estos requisitos a controlar son:

a) La capacidad de las partes. Acerca de qué ley debe regir la capacidad de los cónyuges ha habido diferentes posiciones. Así, un sector doctrinal ha considerado que debe ser el Artículo 9.1 CC la norma de conflicto aplicable para determinar la ley aplicable a la capacidad. Con base en esta norma, debe ser la ley nacional de cada una de las partes la que determine si tenían capacidad para la conclusión del pacto (Calvo $E$ Carrascosa, 2017). Aquí, un problema a solucionar sería un posible conflicto móvil. El Artículo 9.1 CC no congela en el tiempo el punto de conexión; en el caso de cónyuges que han cambiado de nacionalidad entre la firma del pacto y su posterior análisis de validez, sería necesario concretar la ley nacional mediante la cual se va a examinar la capacidad de ese cónyuge ${ }^{5}$. Otro problema se podría encontrar en

5 La solución al conflicto móvil viene de la mano de la tesis conocida como "tesis de la ley anterior". Esto es que para la solución del conflicto móvil es necesario presumir que la norma de conflicto fija la ley aplicable en un momento determinado del tiempo, tal "momento" se corresponde con el nacimiento de la relación jurídica. Esta solución permitiría precisar el derecho aplicable al inicio así, aunque el Artículo 9.1 CC no diga nada, si seguimos esta norma de con- 
los casos en los que la ley personal no coincide con la ley aplicable al pacto $\mathrm{y}$, además, estas leyes establecen diferentes requisitos de capacidad siendo, ad ex., la ley que rige el pacto más exigente que la ley personal o viceversa (Rodríguez Pineau, 2002). Esta situación podría darse en los casos en los que es necesario complementar la capacidad de uno de los contrayentes porque es menor. Así, si la ley que rige la capacidad es más exigente que la ley que rige el acuerdo, debería atenderse a las exigencias de la primera. En el mismo sentido, debería resolverse si la ley aplicable al pacto recogiese criterios más exigentes que la ley personal. En este último supuesto de no cumplirlos, podría dar lugar a la nulidad del pacto por carecer una de las partes de capacidad. Este problema no tendría lugar si la ley aplicable a la capacidad fuera la ley que rige el fondo del pacto, es decir, la ley determinada por el Artículo 9.3 $\mathrm{CC}^{6}$. Que esta norma de conflicto aplicable para determinar la ley lo sea también a la capacidad de las partes permite que la postura de que debería ser una norma de conflicto la utilizada para determinar la ley aplicable a la validez del pacto se reafirme. Además, se evitan situaciones como las anteriormente descritas en las que, ante la no coincidencia de las exigencias de capacidad, habría que atender a dos ordenamientos para evitar situaciones jurídicas claudicantes.

b) El consentimiento. En cuanto a la ley aplicable al consentimiento otorgado por las partes, la doctrina no ha mostrado tampoco una visión unánime. Así, hay autores que consideran que es necesario acudir a la ley nacional de las partes para comprobar si estas han otorgado su consentimiento (Artículo 9.1 CC) (Carrascosa González, 2000, pp. 170-171). Pero hay otro sector que considera que debe ser el Artículo 9.3 CC y, por tanto, la ley aplicable a la validez material del

flicto para determinar la capacidad de los cónyuges para la celebración de un prenup habrá que acudir a la ley nacional que ostentaban al momento de la celebración del pacto, sin que tenga relevancia que, posteriormente, alguno de ellos o ambos cambiaran de nacionalidad. Para un mayor detalle sobre el conflicto móvil y sus posibles soluciones ver Calvo Caravaca y Carrascosa González (2018, pp. 228-230).

6 En la doctrina se ha apoyado ya esta opción. ver al respecto Amores Conradí (1991, pp. 79-84), M. A., artículos 9.2 CC y 9.3 CC. También hay otros ordenamientos jurídicos que consideran que la capacidad de las partes debe analizarse conforme a la ley que rige la validez material o de fondo del pacto, ad ex., en el derecho italiano, Artículo 20, II Ley de derecho internacional privado italiana de 1995. 
pacto la que determine si ha existido consentimiento de las partes (Rodríguez Rodrigo, 2017, p. 601). Esta postura es similar a la seguida en el derecho de los contratos por el Reglamento Roma I7. Este Reglamento considera que la ley elegida por las partes (ley que será la que determine la validez del contrato) es la que debe determinar también el consentimiento de las partes. Desde nuestro punto de vista esta última posición es la más acertada ya que permite que la ley aplicable a la validez material también lo sea a otros aspectos necesarios para determinar si el acuerdo es válido.

c) La forma. El Artículo $11 \mathrm{CC}$ es la norma de conflicto que debe tenerse en cuenta para determinar la ley aplicable a la forma del prenup o acuerdo matrimonial celebrado entre cónyuges. Esta norma, con puntos de conexión alternativos, persigue la validez formal del pacto. De este modo, señala que la forma de los contratos, testamentos y demás actos jurídicos será válida si se adecúa a las solemnidades requeridas por la ley del lugar en el que se otorguen, o la ley que se aplique para determinar la validez material (contenido) del pacto, o la ley personal común o la ley personal de cada uno de los otorgantes, y si se refieren a bienes inmuebles conforme a las formalidades del lugar donde se hallen sitos.

En el caso de los acuerdos prematrimoniales, en el ordenamiento español no hay exigencia formal alguna. Hay autores que consideran que no sería necesario escritura pública para que el prenup sea válido formalmente, a diferencia de lo que sucede con las capitulaciones matrimoniales (Medina, Heras \& Iglesias Caridad, 2014, p. 484). Con base en los artículos 1327 CC y 1280.3 CC, las capitulaciones matrimoniales sí necesitan solemnidad. Por lo tanto, en principio el prenup puede celebrarse de forma privada entre los cónyuges con base en el principio de libertad de forma.

Sin embargo, desde nuestro punto de vista, debido a que consideramos que la naturaleza del acuerdo prematrimonial y la de las capitulaciones matrimoniales son semejantes, no estaría de más, para mostrar la voluntad de las partes y facilitar su prueba, que se tengan en cuenta determinadas

7 Doue L 177/6, de 4 de julio de 2008. 
formalidades. La apreciación de las mismas sería interesante, no tanto para negar la validez del acuerdo en caso de que no se sigan, sino más bien como vía para mostrar la voluntad fehaciente de los futuros cónyuges en la realización del pacto. Exigencias formales, como la escritura pública, son requeridas por el Artículo 231.20 del Código Civil catalán para los pactos en previsión de ruptura. Acudir a un fedatario público permite ventajas como el control de la capacidad y el consentimiento de las partes y del contenido del pacto; además, el acuerdo va a poder ser inscrito en el Registro Civil o en el Registro de la Propiedad. Esta posición estaría en la misma línea de otros ordenamientos como el francés (Artículo 1394 CC francés) o el belga (Artículo 1392 CC belga) donde se exige que el acuerdo prematrimonial se recoja en escritura pública ante notario. En el mismo sentido, en el derecho holandés, además de la escritura pública se exige que el acuerdo se registre para que pueda ser oponible el pacto a terceros (Boele-Woelki \& Braat, 2012, p. 248).

\section{Las posibilidades que brinda el Artículo 9.3 CC}

La autonomía de la voluntad de las partes

En atención a lo antes expuesto, el Artículo 9.3 CC es la norma de conflicto que permite determinar la ley aplicable que permitirá determinar la validez material del prenup. Esta norma va a dejar de ser la norma de conflicto aplicable en poco tiempo ya que el próximo 29 de enero de 2019 entrará en vigor el Reglamento (UE) sobre régimen económico matrimonial. Aun así, como ya señalamos al inicio del presente trabajo, el Artículo 9.3 CC no se va a dejar de aplicar. Esto porque esta norma resulta aplicable a todos los pactos entre cónyuges concluidos antes de la entrada en vigor del citado Reglamento europeo.

Dicho esto, en el momento en el que se redacta el presente trabajo, el control de la validez de un acuerdo prematrimonial pasa por el análisis del pacto conforme a cualquiera de las leyes que determina el Artículo 9.3 CC -la ley aplicable a los efectos del matrimonio, o bien la ley de la nacionalidad o de la residencia habitual de cualquiera de los contrayentes al momento de la celebración del acuerdo-. 
Esta norma de conflicto ofrece a las partes que deseen llevar a cabo un pacto diferentes posibilidades:

a) Autonomía conflictual. La elección de la ley del Estado que quieren que rija su régimen económico matrimonial y demás efectos derivados del matrimonio (Calvo \& Carrascosa, 2017; Rodríguez Pineau, pp. 55-56). Es decir, el prenup podría incluir una única cláusula en la que se determine que la ley aplicable a los efectos del matrimonio es la ley del Estado $X^{8}$. La elección de ley puede ser expresa o tácita. Si es una elección tácita, ad ex., el pacto se rige por la ley de la residencia habitual de la esposa; es necesario que dicha elección sea deducible de las estipulaciones realizadas en el acuerdo (Rodríguez Pineau, 2002, p. 53). Además, el juez o autoridad competente debería comprobar que la autonomía conflictual ejercida por las partes sea válida con independencia del resto de cláusulas que pudiera contener el prenup. También este podría ser un vehículo adecuado no solo para determinar la ley aplicable al pacto o a los efectos, sino que se podrían realizar otras elecciones de ley, como la aplicable al divorcio. En ese caso, para que la elección fuera válida, sería necesario atender a lo dispuesto por los artículos 5 a 7 del Reglamento (UE) No. 1259/2010 del Consejo de 20 de diciembre de 2010, por el que se establece una cooperación reforzada en el ámbito de la ley aplicable al divorcio y a la separación judicial (Rodríguez Pineau, 2002, p. 58).

b) Autonomía material. La elaboración de un pacto ad hoc, un conjunto de cláusulas que se adecúen a las necesidades y expectativas de las partes. Aquí cabe la posibilidad de que las partes elijan un ordenamiento jurídico específico y elaboren conforme al mismo un conjunto de disposiciones a su medida en función de sus necesidades pudiendo pactar hasta donde permita el ordenamiento jurídico que regula el

8 Como señala el profesor J. Carrascosa González (2001, p. 61), que los cónyuges elijan directamente en su acuerdo la ley aplicable a su régimen económico matrimonial no implica fraude ni tampoco se debe presumir que se impone la ley aplicable de un cónyuge frente al otro. Es más, son muchos los Estados que permiten este tipo de elección en sus ordenamientos jurídicos, ad ex., Italia (Artículo 30.1 ley de derecho internacional privado italiano de 1995), Suiza (Artículo 52.1 ley de derecho internacional privado suizo de 1987), Alemania (Artículo 15.2 ley introductoria del Código Civil alemán) o Rumania (21.2 ley de derecho internacional privado rumano de 1992) 
pacto. También es posible identificar el régimen económico matrimonial al hacer referencia únicamente a una institución jurídica extranjera, ad ex., el Versorgungsausgleich alemán o mencionar artículos de normas concretas (Rodríguez Pineau, 2002, p. 58), ad ex., el Artículo 34 y siguientes del Marriage Act finlandés. También puede darse la situación de que, al redactar las cláusulas, las partes combinen más de un ordenamiento jurídico. Es decir, puede darse la situación de que se especifique que el régimen económico matrimonial es el régimen de gananciales español, pero que a la vez se introduzca una cláusula material que permita a los cónyuges comprar bienes sin incluirlos en la masa ganancial conforme a la ley de un ordenamiento diferente al español. Esto podría ser admitido siempre y cuando dicha disposición no sea incompatible con el régimen económico matrimonial aplicable (Rodríguez Pineau, 2002, p. 58).

Es más, las alusiones a otro ordenamiento diferente al que regula el régimen económico matrimonial podrían ir más allá. Ad ex., en un mismo pacto podría establecerse que el régimen económico del matrimonio se rige por el derecho austriaco pero que, en el caso de que los futuros cónyuges, cuyo domicilio van a establecer en España, adquieran bienes inmuebles en ese país, estos bienes se rijan por la ley española. Este tipo de acuerdos donde se recogen estipulaciones que vinculan a más de un ordenamiento traspasa lo material para llevarnos de nuevo a la autonomía conflictual de los cónyuges con base en el Artículo 9.3 CC. Es decir, se podría aplicar a un mismo pacto más de una ley del mismo modo como se puede hacer en derecho de los contratos. Esta cuestión ha sido muy debatida en doctrina (Aguilar, 1996, p. 160; Amores, 1991; Diago, 1999, pp. 195 y ss; Fernández E Sánchez, 2016, pp. 470-471; Garcimartín, 2016, p. 464; Moya, 1991, p. 158). Ambas opciones son perfectamente defendibles, sin embargo, desde nuestro punto de vista, la respuesta a dicha cuestión es afirmativa. La elección voluntaria por las partes de más de una ley aplicable es una forma más de autonomía de la voluntad que puede ser apoyada en espíritu favor validitatis del Artículo 9.3 CC (Carrascosa, 2001, p. 165). Es más, la opción de que un prenup quede regulado por más de una ley, porque así lo consideran las partes, casa también con la naturaleza de este tipo de pactos: autonomía plena de los 
futuros cónyuges en la regulación de los efectos de su matrimonio. Es más, también sería posible aplicar una ley a los efectos personales del matrimonio y otra diferente a los efectos económicos del mismo (Calvo \& Carrascosa, 2017). No obstante, como señala E. Rodríguez Pineau, este ejercicio de fraccionamiento de ley podría encontrar un límite: la identificación del régimen económico matrimonial (Rodríguez Pineau, 2002, p. 68). En otras palabras, debe quedar claro cómo operan los cónyuges en el tráfico jurídico con el fin de que los terceros que se relacionen con estos puedan saber el régimen de titularidades y responsabilidades de los mismos.

c) Combinación de la autonomía conflictual y material. Las partes también podrían combinar las dos opciones anteriores. Así, podrían redactar un prenup eligiendo la ley del Estado conforme a la que va a regir el pacto y acompañar dicha elección con un conjunto de cláusulas donde se detallen aspectos económicos y/o personales que afecten a los futuros cónyuges. Se podría decir que esta es la mejor opción para el tráfico internacional ya que se despejarían las dudas en cuanto a la ley aplicable al régimen económico matrimonial y al resto de efectos derivados del matrimonio.

Puntos de conexión alternativos y sus efectos en la validez del acuerdo

Como ya se ha señalado, los puntos de conexión del Artículo 9.3 CC son puntos de conexión alternativos, en definitiva, buscan la validez del pacto.

Así, el primer punto de conexión conforme al que se puede estudiar la validez del pacto podría ser la ley aplicable a los efectos del matrimonio. En realidad, el Artículo 9.3 CC no es la norma de conflicto aplicable a los efectos derivados del matrimonio. Para tal fin existe el Artículo 9.2 CC. No obstante, cuanto más regule el pacto prematrimonial o posmatrimonial sobre los efectos del matrimonio, menos protagonismo tendrá el Artículo 9.2 CC en la determinación de la ley aplicable a los mismos (Calvo \& Carrascosa, 2017). Así, puede darse la situación de que el prenup regule únicamente el régimen económico matrimonial al que se van a someter los cónyuges, pero no diga nada sobre los efectos personales del matrimonio. En ese caso, para determinar la ley aplicable que rige los 
efectos personales del matrimonio será necesario acudir a las conexiones que recoge el Artículo 9.2 CC. Es posible que los artículos 9.3 CC y 9.2 CC lleven a la misma ley, lo que dejaría, por tanto, todos los efectos del matrimonio bajo una única ley, pero también puede que no sea así.

El segundo punto de conexión es la ley nacional de cualquiera de las partes. Aquí, el legislador sí se preocupó por el conflicto móvil al congelar el punto de conexión en el tiempo ya que debe atender a la ley nacional común o de uno de los cónyuges al momento del otorgamiento.

El tercer punto de conexión es la residencia habitual de cualquiera de las partes al tiempo del otorgamiento.

El hecho de que los puntos de conexión sean alternativos da lugar a que el acuerdo entre los futuros cónyuges pueda ser válido conforme a más de una ley. En concreto, se podrían barajar hasta cinco posibles leyes; que sean cinco o dos dependerá del grado de internacionalidad del supuesto. En ese caso, surge la duda de qué ley es la que debe elegirse como la "ley rectora del pacto". Dicha elección es necesaria para, ad ex., interpretar las disposiciones del acuerdo. Imaginemos que española y francés celebran un prenup. En el mismo señalan que el régimen económico matrimonial aplicable es el régimen legal de gananciales y estipulan su liquidación en el mismo acuerdo. En ninguna de las cláusulas señalan cuál es el ordenamiento aplicable a dicho régimen elegido ni tampoco al pacto. Por lo tanto, será necesario llegar a la ley concreta que rige el pacto para saber si sus estipulaciones son válidas. Con base en el Artículo 9.3 CC, dicho acuerdo podría ser válido conforme a la ley española (ley personal de ella) o conforme a la ley francesa (ley personal de él), ya que el pacto no contradice ninguno de los dos ordenamientos pero, ¿cuál de las dos leyes debería elegir la autoridad que deba analizar el acuerdo? Para saber los derechos y deberes de los cónyuges en el momento de la liquidación, ¿a qué norma se debe acudir? ¿Al Código Civil francés o al Código Civil español? Aquí la doctrina ha puesto dos posiciones en relieve:

a) Jerarquización de las conexiones. Según esta tesis, es necesaria la conversión de los puntos de conexión alternativos en jerarquizados. Así se permitirá elegir la ley rectora del acuerdo entre los cónyuges cuando haya más de una ley que les dé validez. De este modo, habría que 
acudir, en primer lugar, a la primera conexión que recoge el Artículo 9.3 CC: la ley que rige los efectos del matrimonio (ex. Artículo 9.2 CC); si dicha ley hace válido el acuerdo, debe prevalecer sobre el resto de conexiones (Fontanellas, 2009, pp. 365 y ss).

b) Vínculos más estrechos. De acuerdo con esta visión, ante un prenup válido por más de una de las leyes que señala el Artículo 9.3 CC, la ley que debería prevalecer sobre el resto debería ser la del país que presentara vínculos más estrechos. Es decir, la prevalencia entre unas u otras conexiones no es la jerarquía, sino el vínculo real de una ley con el asunto (Calvo \& Carrascosa, 2017) ${ }^{9}$. Por seguir con el ejemplo anterior, imaginemos que el matrimonio entre española y francés tiene lugar y que establecen su residencia en Madrid. Dicho prenup podría ser válido conforme a dos leyes (la francesa o la española), pero debería ser el derecho español el que se encargue de determinar aspectos como la interpretación del pacto o la liquidación de su régimen económico matrimonial. La ley española es, de facto, la ley más vinculada a las partes ya que residen habitualmente en España.

La existencia de más de una ley que dé validez al contenido del prenup influye en otra cuestión importante: la forma. Es decir, si al seguir el Artículo 9.3 CC el pacto puede ser válido en cuanto al fondo, conforme a diferentes leyes, ¿qué ley debería determinar los requisitos formales? Cuando estudiamos la norma de conflicto aplicable a la forma (Artículo 11 CC), señalamos que se trataba de una norma de conflicto con puntos de conexión alternativos que compartía con el Artículo 9.3 CC el hecho de buscar la validez del pacto. De este modo, si varias leyes hicieran válido un prenup en cuanto al fondo, debería tenerse en cuenta como ley aplicable a la forma cualquiera de aquellas (de las determinadas conforme al Artículo 9.3 CC); pero, en concreto, ¿cuál debería ser?

El Artículo 11.2 CC precisa que, en el caso de que la ley aplicable al fondo del pacto exija una forma solemne, será necesario atenderla. Una parte de la doctrina y también de la DGRN han entendido que en caso de que varias leyes den validez al pacto en cuanto a su contenido, 
la ley que debe regir la forma es la menos exigente de todas ellas (Calvo \& Carrascosa, 2017). Esta posición podría casar perfectamente con lo establecido por el Artículo 11.2 CC. Este precepto exigiría que la ley aplicable al fondo y a la forma coincidieran cuando la ley aplicable al fondo exija una forma solemne. No hay obstáculo para que, con base en el principio favor validitatis, la elección de la ley aplicable al fondo se realice en función de que dicha ley sea menos exigente en cuanto a lo que de requisitos de forma se trata. La aplicación de la misma ley a aspectos de fondo y de forma evitaría que el pacto fuera nulo. Hay otros autores que consideran que esta unidad fondo/forma también debe ser respetada, pero el criterio de elegir una ley sobre otra es dando relevancia a la ley de los efectos del matrimonio sobre el resto de posibles leyes (Fontanellas, 2009, p. 370). En definitiva, se escoja una u otra opción, lo importante es que el pacto sea válido en su conjunto y sí que es cierto que si la ley aplicable al fondo es la ley que menos requisitos formales exige, más probable será que dicho pacto resulte válido.

\section{La inscripción del acuerdo prematrimonial en los registros públicos españoles}

Una vez otorgado un acuerdo prematrimonial es posible que las partes quieran darle publicidad. Es decir, inscribirlo en un Registro Público. La ley aplicable a la validez del pacto, es decir, la ley determinada por el Artículo 9.3 CC, es la que establecerá si la inscripción es facultativa para las partes o es un requisito necesario para la validez del acuerdo ${ }^{10}$. Además, dicha ley señalará si es necesaria la inscripción para que el pacto sea oponible a terceros. Sin embargo, la ley que rige el registro correspondiente se encarga de establecer cómo puede acceder determinado acto jurídico al mismo ${ }^{11}$. Así, cabría preguntarse si un acuerdo prematrimonial entre español y venezolana, celebrado en el estado de

10 La inscripción en un Registro Público no es una condición para la validez de las capitulaciones matrimoniales en el ordenamiento jurídico español, ver Resolución DGRN de 13 de noviembre de $2015\left(34^{\mathrm{a}}\right)$, Fundamento de Derecho IV.

11 A diferencia de lo que sucede en el ordenamiento español, hay países que sí cuentan con un registro específico para la inscripción de acuerdos entre cónyuges. Esto sucede ad ex., en ordenamientos como el holandés (artículos 1:116 y 1:120 CC holandés) o el alemán (Artículo 1412 CC alemán). 
California, podría inscribirse en el Registro Civil y, de ser así, qué requisitos son necesarios observar.

En primer lugar, es necesario diferenciar entre los prenups celebrados en el extranjero ante autoridad pública extranjera y los prenups celebrados en España ante autoridad pública española. El segundo supuesto no plantea demasiados problemas ya que, al celebrarse en España, ante notario, este deberá comprobar la capacidad de las partes que han prestado su consentimiento y que el pacto es válido tanto en fondo como en forma. La ley que rija el pacto es la que se ocupará de determinar si los extremos anteriores se cumplen. La comprobación de dichos extremos permitirá al notario recoger el pacto en escritura pública.

Un tratamiento diferente merece el acuerdo prematrimonial celebrado en el extranjero ante autoridad pública extranjera ya que, al no ser un notario español el que interviene en la realización del acto, la condición de documento público no existe per se (Artículo 1216 CC); se debe acreditar. A priori, un acuerdo prematrimonial celebrado en el extranjero, ante autoridad extranjera y conforme a derecho extranjero, puede que no tenga demasiada vinculación con el ordenamiento español. Sin embargo, hay supuestos en los que haya cónyuges interesados en que su pacto celebrado en el extranjero acceda a algún Registro Público español, ad ex., matrimonio de ingleses que se instala en Torrevieja y que compra un bien inmueble en dicha localidad. Al acceder el bien al Registro de la Propiedad, quieren hacer constar que existe un pacto prematrimonial donde acordaron que su régimen económico matrimonial es la estricta separación de bienes. Esta mención del pacto en el Registro de la Propiedad facilitaría mucho a los terceros que se relacionaran con este matrimonio, ya que sabrían cuál es el régimen económico matrimonial bajo el que operan y cómo afecta al bien inmueble. Por seguir con el ejemplo, el registrador de la propiedad solo podría inscribir el pacto si se cumplen los siguientes requisitos:

1) El pacto prematrimonial debe ser válido. El encargado del Registro Público correspondiente debe asegurarse de que dicho pacto que va a inscribir es válido. Los extremos que debe controlar son los ya estudiados anteriormente: 1) capacidad de las partes; 2) consentimiento de las mismas; y 3) validez del pacto en fondo y forma. 
2) Debe recogerse en un documento público extranjero. Dicho documento debe haber sido realizado por la autoridad pública extranjera competente en dar fe de ese tipo de actos jurídicos. La denominación de dicha autoridad es indiferente para que dicho documento acceda a un Registro Público español. Lo relevante es que dicho documento se expida conforme a los requisitos legales del país de otorgamiento, que dicha autoridad extranjera sea competente para tal función y esta sea similar a la que realizaría un notario español, el encargado de expedir este tipo de documentos en España (Calvo \& Carrascosa, 2017). Esto se conoce como principio de equivalencia de funciones (Artículo 60, Ley de Cooperación Jurídica Internacional en Materia Civil ${ }^{12}$ y la Disposición Adicional Tercera Ley de Jurisdicción Voluntaria 1.b) ${ }^{13}$. En concreto, para un acuerdo prematrimonial, en el mismo sentido que si se trata de unas capitulaciones matrimoniales, la autoridad pública extranjera debería haber controlado aspectos como la identidad de las partes (juicio de identidad) y su capacidad (juicio de capacidad), del mismo modo a como lo habría hecho un notario español ${ }^{14}$.

3) El documento público extranjero debe ser auténtico. El registrador necesita comprobar que el documento público extranjero es auténtico. Las

12 Boe núm. 182, de 31 de julio de 2015.

13 Boe núm. 158, de 3 de julio de 2015.

14 Ver al respecto la resolución del DGRN de 23 de noviembre de 2006, Fundamentos de Derecho VI y VII, donde se analiza si un acuerdo prematrimonial celebrado en Pakistán entre española y pakistaní puede acceder al Registro Civil Central español. La encargada del Registro Civil Central denegó la inscripción del pacto porque no estaba recogido en escritura pública y, además, no estaba legalizado. La DGRN, órgano encargado de resolver el recurso que presentaron las partes, entendió que la validez de fondo de dicho pacto debía analizarse conforme bien a la ley española o bien a ley pakistaní, de acuerdo al Artículo 9.3 CC. Además, para la validez formal, la DGRN se inclina por la tesis de que ante varias leyes que dan validez al pacto en cuanto al fondo, habría que elegir la menos exigente formalmente. De este modo, si la Ley pakistaní fuera menos exigente formalmente, ad ex., imaginemos que no exige escritura pública y da validez al pacto en cuanto al fondo, deberá ser dicha ley la ley aplicable. Sin embargo, el análisis de validez forma/ fondo no es suficiente para poder inscribir el prenup en el Registro Civil. La DGRN considera que es necesario tener en cuenta los criterios que el ordenamiento jurídico español exige para que los documentos públicos extranjeros desplieguen sus efectos en España. De este modo, es necesario que se trate de un documento público extranjero que, además, debe ser auténtico. En el caso de este prenup fallaron ambos criterios. La DGRN entendió que en atención al principio de equivalencia de funciones el "juicio de identidad" y el "juicio de capacidad" realizado por la autoridad pakistaní no era equivalente al exigido para que unas capitulaciones matrimoniales accedieran a un registro español. Además, tampoco quedaba acreditado que dicho documento fuera auténtico, ya que aunque estaba traducido al español, pero no legalizado o apostillado. Por lo tanto, la inscripción del prenup no pudo realizarse. 
partes, por tanto, en atención a la normativa española aplicable al respecto deberán legalizar el documento público extranjero (Artículo 323.2.2 $2^{\circ}$ Ley 1/2000, de 7 de enero, de Enjuiciamiento Civil, en adelante $\mathrm{LEC}^{15}$ ) o realizar un trámite similar (Apostilla de la Haya) y traducirlo al idioma oficial (Artículo 144 LEC). En concreto, aunque se recoge lo mismo que en la LEC, ver para el Registro Civil los artículos 86 y 88 del Reglamento del Registro Civil ${ }^{16}$ y para el Registro de la Propiedad los artículoss 4 y 36 de la Ley Hipotecaria ${ }^{17}$.

\section{Conclusiones}

Los acuerdos prematrimoniales son pactos que pueden tener especial sentido cuando se trata de un matrimonio internacional. Los efectos de un divorcio pueden ser imprevisibles, sin embargo, si los futuros cónyuges pueden pactar de antemano qué pasaría con su patrimonio pueden resultar de especial utilidad. No obstante, no todo es tan fácil. Esto es así porque, cuando existen elementos extranjeros diferentes en la relación y el acuerdo se presenta ante un juez para que determine su validez, los aspectos de derecho internacional privado que debe tener en cuenta hasta poder determinar la validez del pacto son distintos.

En definitiva, hay que decir que los acuerdos prematrimoniales no son una figura novedosa. Aun así, consideramos que su auge va a ser aún mayor en los próximos años, ya no solo a nivel internacional sino también interno. El nuevo papel de la mujer en la sociedad o la diferente forma de concebir el matrimonio hace que figuras como los acuerdos prematrimoniales cobren protagonismo en el tráfico jurídico. En realidad, este tipo de instrumentos no deja de ser un reflejo de la sociedad actual. Una sociedad que quiere hacer uso de la autonomía de la voluntad también en sus relaciones familiares y no dejar que terceros decidan qué debe suceder cuando el matrimonio llega a su fin.

\footnotetext{
15 BoE núm. 7, de 8 de enero de 2000.

16 BoE núm. 296, de 11 de diciembre de 1958.

17 Boe núm. 58, de 27 de febrero de 1946.
} 


\section{Referencias}

Abarca Junco, A. P. (2004). Los efectos del matrimonio. En A. P. Abarca Junco (dir.), Derecho internacional privado, volumen II, pp. 119 y ss. Madrid: UNED. Aguilar Benítez de Lugo, M. (2006). Los efectos del matrimonio. En M. Aguilar Benítez de Lugo (dir.), Lecciones de Derecho civil internacional (pp. 135-164). Madrid: Tecnos.

Aguilar Ruiz, L. (2014). Los pactos prematrimoniales. Vigencia y actualidad en el nuevo derecho de familia. En L. Díez Picazo (coord.), Estudios jurídicos en homenaje al Profesor José María Miquel (pp. 107-108). Navarra: Aranzadi.

Aguilar Ruiz, L. y Hornero Méndez, C. (2006). Los pactos conyugales de renuncia a la pensión compensatoria: autonomía de la voluntad y control judicial. Revista Jurídica del Notariado, (57), 9 y ss.

Allueva Aznar, L. (2013). Los requisitos para la validez de los pactos en previsión de ruptura matrimonial, Indret, (1/2013), 1-20.

Amores Conrari, M. A. (1991). La nueva ordenación de la ley aplicable a los efectos del matrimonio. Revista Jurídica de Castilla-La Mancha, (11-12), 54 y ss. Anguita Villanueva, L. A. (2010). Acuerdos prematrimoniales: del modelo de los Estados Unidos de América a la realidad española. Estudios Sobre Validez e Ineficacia, (1), 6 y ss. Recuperado de: http://www.codigo-civil.info/nulidad/ lodel/docannexe.php?id=806 (consultado el 9 de mayo de 2016).

Antón Juárez, I. (2015).Acuerdos prematrimoniales: ley aplicable y derecho comparado. Cuadernos de Derecho Transnacional, 7(1), 5-45.

Biemmiller, C. (2014). The uncertain enforceability of prenuptial agreements: Why the "extreme" approach in Pennsylvania is the right approach for review. Drexel L. Review, (6133), 137 y ss.

-Boele-Woelki, K. y Braat B. (2012). Marital agreements and private autonomy in the Netherlands. En J. M. Sherpe (ed.), Marital agreements and private autonomy in comparative perspective (p. 248). Oregon: Hart Publishing.

Bonomi, A. y Steiner, M. (2006). Les régimes matrimoniaux en droit comparé et en droit international privé. Ginebra: Libraire Droz.

Borrás Rodríguez, A. (1991). No discriminación por razón de sexo: derecho internacional privado. Anuario de Derecho Civil, XLIV, 233-249.

Cabanillas Sánchez, A. (2012). Capítulo II: las capitulaciones matrimoniales. En G. Díez-Picazo Giménez (coord.), Derecho de familia (pp. 590-653). Madrid: Thomson Civitas. 
Carrillo Pozo, L. F. (2012). Eficacia en España de las resoluciones extranjeras en materia de efectos económicos del matrimonio. Cuadernos de Derecho Transnacional, 4(1), 86-121.

Calvo Caravaca, A. L. y Carrascosa González, J. (2016). Problemas de aplicación de la norma de conflicto. En A. L. Calvo Caravaca y J. Carrascosa González (dirs.), Derecho internacional privado, volumen I (pp. 475-478). Granada: Comares.

Calvo Caravaca, A. L. y Carrascosa González, J. (2017). Efectos del matrimonio. En A. L. Calvo Caravaca y J. Carrascosa González (dirs.), Derecho internacional privado, volumen II (pp. 213-270). Granada: Comares.

Calvo Caravaca, A. L. y Carrascosa González, J. (2018). Derecho aplicable (I). Técnicas de reglamentación. La norma de conflicto. En A. L. Calvo Caravaca y J. Carrascosa González (dirs.), Derecho internacional privado, volumen I (pp. 228-230). Granada: Comares.

Carrascosa González, J. (2000). Matrimonio y elección de ley. Estudios de DIPr. Granada: Comares.

Cervilla Garzón, M. D. (2013). Los acuerdos prematrimoniales en previsión de ruptura: un estudio de derecho comparado. Valencia: Tirant Lo Blanch.

Clark, B. (2010). Prenuptial contracts in English law: Capricious outcomes or legislative clarification. Journal of Social Welfare E Family Law, 32(3), 237-245.

Clark, B. (2011). Ante-nuptial contracts after Radmacher: An impermissible gloss? Journal of Social Welfare E Family Law, 33(1), 14-24.

Curry, A. (2010). Comment the uniform premarital agreement act and its variations throughout the States. 23 Journal of the American Academy of Matrimonial Lawyers, 355. Recuperado de http://www.aaml.org/sites/default/ files/MAT206_3.pdf

Diago Diago, P. (1999). Pactos o capitulaciones matrimoniales en derecho internacional privado. Aragón: El justicia de Aragón.

Espinar Vicente, J. M. (1996). El matrimonio y las familias en el sistema español de derecho internacional privado. Navarra: Civitas.

Esplugues Mota, C., Iglesias Buhigues, J. L. y Palao Moreno, G. (2015). Derecho internacional privado. Valencia: Tirant Lo Blanch.

Fernández Rozas, J. C. y Sánchez Lorenzo, S. (2016). Derecho internacional privado. Navarra: Civitas-Thomson Reuters.

Fernández Rozas, J. C. (2016). Un hito más en la comunitarización del derecho internacional privado: regímenes matrimoniales y efectos patrimoniales de las uniones registradas. La Ley Unión Europea, (40), 1-29. 
Ferrer Riba, J. (2012). Marital agreements and private autonomy in Spain. En J. M. Sherpe (ed.), Marital agreements and private autonomy in comparative perspective, pp. 350-369. Oregon: Hart Publishing.

Fontanellas Morell, J. M. (2009). Reflexiones sobre el apartado 3 del Artículo 9 del Código Civil. En M. T. Areces Piñol (coord.), Estudios jurídicos sobre persona y familia (pp. 355-370). Granada: Comares.

Iriarte Ángel, J. L. (2000). Capítulo IV. Normas de derecho internacional privado. En I. Sierra Gil de la Cuesta (coord.), Comentarios al Código Civil, tomo I, artículos 1 al 89 (pp. 403-522). Barcelona: Bosch.

García Rubio, M. P. (2003). Los pactos prematrimoniales de renuncia a la pensión compensatoria en el Código Civil. Anuario de Derecho civil, IV, 1653-1674. González del Pozo, J. P. (2008). Acuerdos y contratos prematrimoniales (I). Boletin de Derecho de Familia, (81), 1 y ss.

Harris-Short S. y Miles, J. (2011). Family law: Text, cases and materials. Oxford: Oxford University Press.

Mark Ellman, I. (2012). Marital agreements and private autonomy in the United States. En J. M. Sherpe (ed.), Marital agreements and private autonomy in comparative perspective (pp. 404-429). Oregon: Hart Publishing.

Martínez Escribano, C. (2011). Pactos prematrimoniales. Madrid:Tecnos.

Medina Alcoz, M. (2015). Pactos prematrimoniales, pacta sunt servanda y modificación sobrevenida de las circunstancias. En M.Pereña Vicente y P. Delgado Martín (Dirs.), Nuevas orientaciones del derecho civil en Europa (pp. 773-774). Navarra: Thomson Reuters-Aranzadi.

Medina Alcoz M. (2014). Capitulaciones matrimoniales y pactos prenupciales. En M. Yzquierdo Tolsada (dir.), Contratos civiles, mercantiles, públicos, laborales e internacionales, con sus implicaciones tributarias, pp. 479-483. Navarra: Thomson Reuters-Aranzadi.

Meehan, A. (2010). Rademaher:What practitioners need from the Supreme Court. Family Law, 40(3), 253-258.

Miles, J. (2012). Marital agreements and private autonomy in England and Wales.

En M. Sherpe (Editor), Marital agreements and private autonomy in comparative perspective, pp. 89-121. Oxford-Portland-Oregon: Hart Publishing.

Pérez Martín, A. J. (2009). Pactos prematrimoniales. Capitulaciones matrimoniales. Convenio regulador. Procedimiento consensual. Valladolid: Lex Nova.

Pintens, W. (2012). Marital agreements and private autonomy in France and Belgium. En M. Sherpe (ed.), Marital agreements and private autonomy in comparative perspective (pp. 89-121). Oxford-Portland-Oregon: Hart Publishing. 
Pinto Andrade, C. (2010). Pactos matrimoniales en previsión de ruptura. Barcelona: Bosch.

Rebolledo Varela, A. L. (2008). Pactos en previsión de la ruptura matrimonial. F. J. Gómez Gálligo (coord.), Libro homenaje al profesor Cuadrado Iglesias, volumen I (pp. 735-755). Navarra: Aranzadi.

Rodríguez Guitián, A. (2018). Los pactos preruptura conyugal. Navarra: Thomson Reuters Aranzadi.

Rodríguez Pineau, E. (2002). Régimen económico matrimonial: aspectos internacionales. Granada: Comares.

Rodríguez Rodrigo, J. (2017). Capítulo 29. Régimen económico matrimonial. Aspectos internacionales. En M. Yzquierdo Tolsada y M. Cuena Casas (dirs.), Tratado de derecho de familia, volumen 4 (pp. 489-620). Navarra: Aranzadi. Sherpe J. M. (2012). Los acuerdos prematrimoniales en Inglaterra y Gales tras Radmacher $v$. Granatino. Indret. Recuperado de http://www.indret.com/ pdf/890_es.pdf 